\title{
A grand convergence in mortality is possible: comment on Global Health 2035
}

\author{
Ole Frithjof Norheim ${ }^{\star}$
}

Abstract

The grand challenge in global health is the inequality in mortality and life expectancy between countries and within countries. According to Global Health 2035, the Lancet Commission celebrating the $20^{\text {th }}$ anniversary of the World Development Report (WDR) of 1993, the world now has the unique opportunity to achieve a grand convergence in global mortality within a generation. This article comments on the main findings and recommendations of the Global Health 2035.

Keywords: Global Health, Investing in Health, Macro-Economic Benefits, Mortality Inequality

Copyright: @ 2014 by Kerman University of Medical Sciences

Citation: Norheim OF. A grand convergence in mortality is possible: comment on Global Health 2035. Int J Health Policy Manag 2014; 2: 1-3. doi: 10.15171/ijhpm.2014.01
Article History:

Received: 19 December 2013

Accepted: 6 January 2014

ePublished: 9 January 2014

Correspondence to: Ole Frithjof Norheim Email: Ole.norheim@igs.uib.no
$\mathrm{T}$ The controversial, but later widely celebrated, World Bank Report of 1993, Investing in Health, moved finance ministers all over the world to reconsider insufficient funding for health in low- and middle-income countries $(1,2)$. Global Health Initiatives, such as the Global Fund to Fight AIDS, Tuberculosis and Malaria; and the Global Alliance for Vaccines and Immunization (GAVI) were launched in the same spirit: investing in health is necessary, a moral imperative, and if done wisely it will provide large economic returns (3). When Bill Gates moved into philanthropy, the report that inspired him most was World Development Report (WDR) 1993 (4). When the former Norwegian Prime Minister Jens Stoltenberg announced the first billion for GAVI (together with Gates), he referred to the substantial returns from investing in vaccines (5) - a "drop of gold", as they were called in The Economist (6). When Gro Harlem Brundtland became the Director General of the World Health Organization (WHO) in 1998, the first thing she did was to call upon Jeffrey Sachs to summarize evidence about the macro-economic benefits of improving health (7). She also endorsed the second main message of WDR 1993priority setting according to cost-effectiveness. She saw priority setting as a means to move toward universal health coverage: "if services are to be provided for all, then not all services can be provided. The most cost-effective services should be provided first" (8).

The last decade in global health has been characterized by optimism (9). The number of child deaths dropped from 11.9 million deaths in 1990 to 7.7 million deaths in 2010, a more rapid decline than ever expected (10). More people are sleeping under insecticide-treated mosquito nets than ever, and more people have access to Antiretroviral Therapies (ARTs) than anyone hoped for when UNAIDS, WHO, and others in 2003 launched the " 3 by 5 " initiative. In 2012, more than 9.7 million people living with HIV were receiving ARTs in low- and middle-income countries (11). If we look at the overall health outcomes, life expectancy in low-income countries increased with six years for males and females from the year 2000 to 2011 (12). That is more than half a year average health improvement in the worst-off populations every year since 2000 .

\section{The challenge}

And yet, starting with the financial crisis in 2008, Development Assistance for Health (DAH) has flattened out, countries are told to increase their own funding for antiretrovirals for HIV, and there are still vast inequalities in mortality and morbidity (13). Many countries are afraid that they will be left behind. The burden of disease is substantial, with many countries undergoing a demographic transition so that they now experience a double or even a triple burden: the high burden from communicable diseases, the emerging chronic diseases, and the persistent high numbers of healthy life years lost from injuries (14). Access to a wide range of modern health services, such as prevention and treatment for cardiovascular disease and cancer, is only available for those who can afford them (15). Universal health coverage is, but a distant dream. The unfinished agenda is still with us. The grand global challenge is still inequality in mortality and life expectancy, between countries and within countries. The difference in life expectancy at birth between high- and lowincome countries was 20 years in $2011 ; 60.2$ in low-income countries and 80.2 in high-income countries (12). Within countries, such as in Ethiopia-one of the African countries with the largest economic growth, but still one of the poorest countries in the world-the estimated difference between the poorest and the not so poor upper quintile was nine years in 2011 (16). If we apply another inequality measure-Absolute Length of life Inequality (ALI): the average difference in life expectancy between two randomly picked individuals in a population-the difference was 27.6 years in Ethiopia in 2011 (16). Some live long and healthy lives, but too many have their lives cut short prematurely.

And yet, change is possible. A new optimism is justified. According to Global Health 2035, the Lancet Commission 
celebrating the $20^{\text {th }}$ anniversary of the WDR 1993, the world now has the unique opportunity to achieve a grand convergence in global mortality within a generation.

\section{Investing in health}

Global Health 2035 is an ambitious new investment framework to begin closing this health gap. Written by a group of economists and global health experts, Global Health 2035 argues that a convergence is possible for infectious, child, and maternal mortality. Major reductions in the incidence and consequences of Non-Communicable Diseases (NCDs) are also within reach. Their findings can be summarized in four key points:

1. A "grand convergence" in health is achievable within our lifetimes

Countries can learn from middle-income countries that have made wise investments in health. The report points to the "4C countries"-Chile, China, Costa Rica, and Cubawhich started off at similar levels of income and mortality as today's low-income countries. They are now among the bestperforming middle-income countries. Low-income countries can, and should, scale up existing (and new) interventions targeting reproductive, maternal, neonatal, and child health conditions, as well as infectious diseases such as Malaria, TB, and HIV/AIDS. Since the 4Cs have achieved such a remarkable mortality reduction in these areas, we know it is technologically and medically feasible. The opportunity is here, the impact on health would be immense, and the cost not unreasonable if seen in the correct perspective.

The Commission estimates that for 34 low-income countries, the extra cost will be about 23 billion US dollars annually from 2016-2025, rising to around 27 billion US dollars annually from 2026-2035. For lower-middle-income countries the extra cost will be about 38 billion US dollars annually from 20162025 , rising to around 53 billion US dollars annually from 2026-2035. These are large numbers, but what is remarkable is that the expected economic growth of middle-income countries will allow these countries to finance "convergence" entirely from domestic sources. The issue is political will and capacity to increase mobilization of domestic resources for health, to make inter-sectoral reallocations, and to improve technical efficiency (17). Low-income countries will require some external assistance, but they will be able to finance much of the incremental cost of achieving "convergence" themselves.

\section{The returns to investing in health are even greater than originally estimated}

Earlier macro-economic studies have explored and documented the national income gains from improved population health, not least increasing life expectancy. What is new in this report is that the Commission has taken what is called "full income" into account. Full income values not only economic productivity gains, but assigns also a monetary value to the intrinsic benefits of increased life expectancy. By combining demographic estimates of increasing life expectancy with the value of a statistics life (18), converted to the value of additional life years (8), the direct value of health improvements is captured in a way, and with results, that are truly noteworthy. For example, by looking only at "convergence" of under-five mortality, the increase in life expectancy could be up to 6.7 years for lowincome countries (19). This, by reflection, translates to a huge benefit measured in monetary terms. The Commission estimates that for every dollar invested in convergence-related interventions, the economic benefits are 9-20 times higher (8). That is, indeed, a remarkable return on investments. The message is clear: investing in interventions targeting infectious diseases, reproductive, maternal, neonatal, and child health conditions is not only cost-saving in the long run; it is also a very good investment.

\section{Fiscal policies and well-designed interventions can dramatically curb non-communicable diseases and injuries}

The commission also looked at emerging chronic diseases and injuries. They propose a package of essential interventions consisting of cost-effective clinical interventions for NCDs and injuries, as well as powerful public health interventions such as increasing taxes on tobacco and alcohol (in countries where this has not been done) and reducing subsidies on items such as fossil fuels, which produce air pollutants that cause NCDs. For example, a 50\% tax on tobacco could prevent 20 million deaths in China and generate 20 billion US dollars additional revenue annually.

\section{Progressive universalism is an efficient way to achieve health and financial protection}

From my perspective, the most remarkable conclusion, from this commission of economists and global health experts, is that "progressive universalism" - a term coined by Davidson Gwatkin and defined as a pro-poor pathway toward Universal Health Coverage (UHC) (20) - is an efficient way to achieve health and financial protection. The first pathway towards UHC that they recommend, and which I support, makes the "convergence interventions" the key. UHC should first protect everyone "by covering essential healthcare interventions to achieve convergence and tackle NCDs and injuries. This pathway would directly benefit the poor, because they are disproportionately affected by these problems" (8). Later, and in addition, a broader package funded through a wider range of financing mechanisms can be offered.

\section{Conclusion}

In summary, there are grounds for optimism in global health. Low- and middle-income countries can:

1. Aim for convergence in mortality and life expectancy with the $4 \mathrm{Cs}$, the best-performing countries, within a generation.

2. Define and scale up essential services targeting infectious diseases, reproductive, maternal, neonatal, and child health conditions, and expand the range of services targeting NCDs and injuries.

3. Merge the idea of convergence interventions and the goal of progressive realization of universal health coverage. Essential interventions are good investments, they are the first important step on the path to UHC, and they will improve both health and provide financial protection.

4. Increase revenue for health from economic growth, increased mobilization of domestic resources, intersectoral reallocations and efficiency gains. For the poorest countries, external resources are needed.

5. Justify this use of resources with reference to the fact that for every dollar invested in essential services aiming at "convergence", the economic benefits are 9-20 times higher. 
Now that we have a better idea of what to do, and why, the next step is to understand better how. The challenge remains: Massive health inequalities still exist across countries. The vast majority of people who die from preventable deaths caused by infectious diseases or maternal and child health conditions live in low- and lower-middle income countries. A convergence is possible, but we are not there yet.

\section{Ethical issues}

Not applicable.

\section{Competing interests}

The author declares that he has no competing interests.

Author's contribution

OFN is the single author of the manuscript.

\section{References}

1. World Bank. World Development Report 1993. Investing in Health. Oxford: Oxford University Press; 1993

2. Horton R. Investing in health: why, what, and three reflections. Lancet 2013; 382: 1859-61.

3. Dybul M. A grand convergence and a historic opportunity. Lancet 2013; 382: e38-9.

4. Specter M.What money can buy. The New Yorker [serial on the internet]. [updated 2005 October 24; cited 2013 December 10]; Available from: http://www.newyorker.com/archive/2005/10/24/051024fa fact specter

5. Stoltenberg J. Our children: the key to our common future. Lancet 2006; 368: 1042-4.

6. Anonymous. Vaccination: Adrop of pure gold. The Economist [serial on the internet]. [updated 2005 October 13; cited 2013 December 10]; Available from: http://www.economist.com/node/5017166

7. World Health Organization (WHO). Macroeconomics and health: Investing in health for economic development. Report of the Commission on Macroeconomics and Health [internet]. 2001. Available from: http://whqlibdoc.who.int/ publications/2001/924154550x.pdf

8. Jamison D, Summers L, Alleyne G, Arrow K, Berkley S, Binagwaho $A$, et al. Global health 2035: a world converging within a generation.
Lancet 2013; 382: 1895-955.

9. Deaton A. The great escape. New Haven: Princeton University Press; 2013.

10. Rajaratnam JK, Marcus JR, Flaxman AD, Wang $\mathrm{H}$, Levin-Rector A, Dwyer L, et al. Neonatal, postneonatal, childhood, and under-5 mortality for 187 countries, 1970-2010: a systematic analysis of progress towards Millennium Development Goal 4. Lancet 2010; 375: 1988-2008.

11. World Health Organization (WHO). HIVIAIDS. Fact sheet No 360 Geneva: WHO; 2013.

12. World Health Organization (WHO). WHO Life Tables for Member States [internet]. 2011. [cited 2013 June 1]. Available from: http:// apps.who.int/whosis/database/life_tables/life_tables.cfm

13. Institute for Health Metrics and Evaluation (IHME). Financing Global Health 2012: The End of the Golden Age? Seattle: IHME; 2013.

14. Murray CJL, Vos T, Lozano R, Naghavi M, Flaxman AD, Michaud C, Ezzati M, et al. Disability-adjusted life years (DALYs) for 291 diseases and injuries in 21 regions, 1990-2010: a systematic analysis for the Global Burden of Disease Study 2010. Lancet 2012; 380: 2197-223.

15. Chisholm D, Evans D. Improving health system efficiency as a means of moving towards universal coverage. Background paper to World Health Report 2010 [internet]. 2010. Available from: http://www.who. int/healthsystems/topics/financing/healthreport/28UCefficiency.pdf

16. Tranvåg EJ, Ali M, Norheim OF. Health inequalities in Ethiopia: modeling inequalities in length of life within and between population groups. Int J Equity Health 2013; 12: 52.

17. World Health Organization (WHO). The World Health Report Health Systems Financing: The Path to Universal Coverage. Geneva: WHO; 2010.

18. Hammitt J, Robinson L. The income elasticity of the value per statistical life: transferring estimates between high and low income populations. Journal of Benefit-Cost Analysis 2011; 2: 1-27.

19. Norheim OF. Estimated impact on life expectancy and mortality inequality of reducing under-five, maternal, tuberculosis and HIV mortality to a level comparable with four well-performing countries (China, Chile, Costa Rica and Cuba). Commission on Investing in Health Working Paper [internet]. 2013. [cited 2013 October 22]. Available from: http://globalhealth2035.org

20. Gwatkin DR, Ergo A. Universal health coverage: friend or foe of health equity? Lancet 2011 ; 377: 2160-1. 